\title{
A MODEL OF EYE CARE SERVICE IN THE EASTERN REGION OF NEPAL
}

\author{
Singh S K${ }^{1}$, Pokharel G $P^{2}$
}

\section{ABSTRACT}

Mechi Eye Care Center was established in a rented building in Nov. 1996 with the help of Eye Care Himalaya, The Netherlands. In the last four and half years patient flow has increased gradually and the present facility is stretched to the limit.

Provision of efficient and good quality treatment, close monitoring on attainment of good surgical quality and visual outcome are the main aims of this eye centre. Community involvement (such as active participation in screening camp and land donation for new proposed eye hospital) has been exemplary. Trained Ophthalmic assistants are fully utilized thus enabling Ophthalmologists to devote their time in surgery and examination of referred patients. Preventive maintenance of instruments $\&$ equipment is a routine practice in this eye center.

It is facing the problem with the space and the human resources (mainly Ophthalmologist). Eye Care Himalaya has planned to construct a new building of the hospital and train required human resources. We hope that after completion of the new hospital building and with proper and sufficient number of trained manpower at least one thousand patients can be examined and two hundred patients can be operated every day. Thus, the Hospital will be a gift to the blind people of this region to prevent and cure their blindness and at the same time, it could play a significant role to eliminate the avoidable blindness in this part of the world and contribute to the Mission - Vision 2020: The Right to Sight.

1. Mechi Eye Care Centre, Birtamod, Jhapa, Nepal.

2. World Health Organization, Geneva - 27, Switzerland.

Address for correspondence : $\quad$ Dr. S. K. Singh, MD, Ophthalmologist Incharge

Mechi Eye Care Centre, Birtamod

Jhapa, Nepal.

Phone No.: 023-40153, 023-41093. Email: mecc@fech.wlink.com.np 


\section{INTRODUCTION}

Nepal is one of the ten poorest countries in the world with an average family income of less than $\$ 150$ per year. ${ }^{1}$ Nepal is divided into five development regions, 14 zones and 75 districts. Geographically, Terai (plain land) covers $33 \%$, hill region covers $42 \%$, and mountain region covers $25 \%$. According to National Population Census of 2001, Nepal's population was 23.2 million.

The reported prevalence of blindness varies from 1-4 per 1000 population in the communities with good economic and health status, compared with 5-15 per 1000 in communities with poor economic and health status. , $3,4,5,6,7,8,9$ Age related macular degeneration, Glaucoma, Diabetic Retinopathy and congenital diseases are the major causes of blindness in the communities with good economic and health status whereas Cataract, Glaucoma, Trachoma/Scar, Onchocerciasis, Xerophthalmia and other causes of childhood blindness are the major causes of blindness in the communities with poor economic and health status..$^{10,11,12,13}$ According to the Nepal Blindness Survey of $1981,{ }^{14}$ prevalence of blindness in Nepal was $0.87 \%$. Cataract, Corneal opacity, Glaucoma and Retinal diseases were found to be the major causes of blindness. $80.2 \%$ of the blindness was avoidable or curable.

Mechi Eye Care Center was established in a rented building in Birtamod, Jhapa in November 1996. In the beginning a surgical eye camp was carried out where 442 cataract surgeries were performed and more than five thousand patients were examined and treated. Clinical services were started from December 1, 1996 with the help of one Ophthalmologist and five ophthalmic assistants. Since the very beginning Mechi Eye Care Center is providing the eye care services to the people of this zone through the hospital based service and the community based programs.

\section{INFRASTRUCTURE}

It consists of Out patient department, Operation theatre, In-patient department, and Administrative office.

\section{OUTPATIENT DEPARTMENT}

It is situated in the ground floor in about $1800 \mathrm{Sq}$. feet. To function the outpatient department smoothly an outpatient department protocol has been developed and is in use. Initial screening of patients are done by the ophthalmic assistants and if needed they are referred to the ophthalmologist. Minor surgical procedures like entropion/ectropion correction; chalazian incision and curettage are carried out in the treatment room on the OPD basis.

\section{OPERATION THEATRE}

It is situated on the top floor. The setup of Operation theatre is mainly for the surgery of the anterior segment disorders. It is well supported by good microscopes, vitrectomy machine and phacomachine. Fumigation is carried out weekly in the operation theatre.

\section{IN-PATIENT DEPARTMENT}

It is in the first floor. There are fifteen beds in paying ward and fourty beds in the general ward, which is in the 'hut' like setting.

\section{MICROBIOLOGY LABORATORY}

A small microbiology laboratory with a microscope has been setup in the duty room of in patient department section. Facility for Gram staining and $\mathrm{KOH}$ mount is available. 


\section{SUPPORTING SERVICES}

Yag Laser facility, facility for central visual field analysis and biometry are also available.

\section{HUMAN RESOURCES}

At present one ophthalmologist (supported by a second ophthalmologist from time to time), two senior ophthalmic assistants, seven ophthalmic assistants, one senior administrative assistant, one registration clerk, two primary eye care workers, three cleaners, four guards and one driver are working in the Center.

\section{HOSPITAL SERVICES}

Ophthalmic assistants do regular screening of the patient. They usually dispose the patients with refractive error and patients with minor ophthalmic problems.

\section{Fig. 1. Mechi Eye Care Center: an overview 2000-01}

INPUT OUTPUT

\begin{tabular}{|c|c|}
\hline 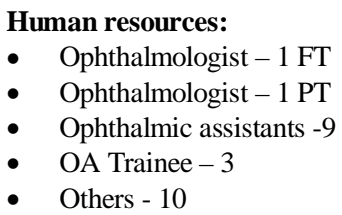 & $\begin{array}{l}\text { Hospital based Services } \\
\text { (annual): } \\
\text { - } \quad \text { OPD }-40,000 \\
\text { - } \quad \text { Surgeries }-2,513\end{array}$ \\
\hline $\begin{array}{l}\text { Infrastructure: } \\
\text { - } \quad \mathrm{OPD}-1800 \mathrm{sq} \mathrm{ft} \text { area } \\
\text { - } \quad \mathrm{OT}-1800 \mathrm{sq} \mathrm{ft} \\
\text { - } \quad \mathrm{IPD}-3700 \mathrm{sq} \mathrm{ft} \\
\text { - } \quad \text { Office, etc }-1100 \mathrm{sq} \mathrm{ft}\end{array}$ & $\begin{array}{ll}\text { Outreach: } \\
\text { - } & \text { Screening camps }-40 \\
\text { - } & \text { Satellite clinics }-52 \\
\text { - } & \text { Surgical camps }-2 \\
\text { - } & \text { School screening - } 10 \\
\text { - } & \text { Primary Eye Care } \\
& \text { centers - } 1\end{array}$ \\
\hline $\begin{array}{ll}\text { Major equipment: } \\
\text { - } & \text { Microscope }-3 \\
\text { - } & \text { YAG laser }-1 \\
\text { - } & \text { Phaco machine }-1 \\
\text { - } & \text { Slit lamp - } 3 \\
\text { - } & \text { A-Scan - 1 }\end{array}$ & $\begin{array}{ll}\text { Training: } \\
\text { - } \quad \text { Ophthalmic assistants }-3 \\
\text { - } \quad \text { Primary eye care worker } 3 \\
\text { - } \quad \text { Low vision - } 2\end{array}$ \\
\hline $\begin{array}{l}\text { Microbiology Lab: } \\
\text { - } \quad \text { Microscope }-1 \\
\text { - } \quad \text { Glass slides - } 100\end{array}$ & $\begin{array}{l}\text { Microbiology Investigation: } \\
\text { (annual) } \\
\text { - } \quad \text { GRAM Stain }-150 \\
\text { - } \quad \text { KOH Mount - } 150\end{array}$ \\
\hline
\end{tabular}


Other than routine anterior segment surgeries, Phacoemulsification and Penetrating Keratoplasty surgery are carried out on a regular basis. Patients from near vicinity are encouraged to undergo cataract surgery on day care basis. Keeping in mind the different economic groups of people in the community, different surgical package for the different group of patients have been designed. Regular visual acuity outcome (in 2 months) is closely monitored and discussed among the clinical staff. Patients operated in the center are provided yag laser capsulotomy free of cost. On one hand, patients are encouraged to pay for their surgery and on other hand not even the poorest of the poor patients walk away from the center without treatment. As the patients are encouraged to pay they understand the value of treatment.

\section{COMMUNITY EYE CARE PROGRAM}

Screening eye camps are carried out in the area connected by the motorable road. One to two surgical eye camps in a year are carried out in the hills that are not connected by road or the area that is difficult to reach by road. School screening program is conducted regularly to rule out any visual problems in the children. Similarly screening programs are carried out in the blind school to screen those children who could be helped with the help of low vision devices. Various social organizations (Lions Club, Nepal Red Cross Society, Jaycees), religious organizations (Reiyukai, Krishna Pranami Youth Council, Sai Samiti) and village development committee have played an active role to conduct screening and surgical eye camps. Communities are actively involved in the screening camps.
Cataract surgery service is provided free of charge to the patients from the screening camps and surgical camps. However, the patients from the screening camps are encouraged to pay the direct cost of the intra-ocular lens (IOL). A local organizer support patients who are unable to pay and if local organizers are unable to pay then the hospital has to bear the cost of the intra-ocular lens. In surgical camps, intra-ocular lenses are provided at a subsidized price. Like in the screening camps intraocular lenses are provided for free to those poor patients who cannot afford to pay.

\section{TRAINING}

Ophthalmic Assistant training, Eye Workers training and Primary Eye Care training is carried out. For the ophthalmic assistant training, high school passed candidates are selected on the basis of entrance examination. For the eye workers training class eight passed candidates are selected. Selected candidates undergo on the job training. One week long training on ocular diseases and ocular emergencies is provided to Health Assistants (HA) who work in the primary health care system of the Ministry of Health. So far a total of 37 have undergone this training.

\section{INSTRUMENT / EQUIPMENT PREVENTIVE MAINTENANCE}

Periodically instruments and equipment are cleaned and repaired. Emphasis is given on preventing any major breakdown. Bulbs and fuses are kept in stock and voltage stabilizers and UPS system are installed. 
Table I : Clinical Activities : Services of Mechi Eye Care Center

\begin{tabular}{|c|c|c|c|c|c|}
\hline $\begin{array}{c}\text { Services / } \\
\text { Year }\end{array}$ & $\begin{array}{c}\text { OPD } \\
\text { Hospital }\end{array}$ & $\begin{array}{c}\text { Surgeries } \\
\text { Hospital }\end{array}$ & $\begin{array}{c}\text { OPD } \\
\text { Eye Camp }\end{array}$ & $\begin{array}{c}\text { Surgeries } \\
\text { Eye Camp }\end{array}$ & $\begin{array}{c}\text { School } \\
\text { Screening }\end{array}$ \\
\hline Dec 1996 & 813 & 36 & 4925 & 442 & \\
\hline 1997 & 19354 & 583 & 3865 & 239 & 640 \\
\hline 1998 & 24614 & 925 & 10027 & 1136 & \\
\hline 1999 & 31081 & 1165 & 5647 & 540 & \\
\hline 2000 & 35505 & 1555 & 5948 & 569 & \\
\hline 2001 & 41934 & 2304 & 9073 & 535 & 4066 \\
\hline
\end{tabular}

\section{FINANCIAL INPUT AND COST RECOVERY}

During the fiscal year 2000/2001, 2513 cataract surgeries were performed and over 40,000 out patients were examined. This provided a cost recovery of $87 \%$ of the cash running cost of the Center i.e. excluding cost of outreach activities, training and depreciation (table 2). The charges for services are: OPD- US Dollar 0.30, subsidized cataract surgery with IOL- US Dollar 13, general cataract surgery with IOL- US Dollar 21 and Phacoemulsification surgery with IOL-US Dollar 80.

Projections show that by increasing the number of cataract surgeries to 3,500 and maintaining right mix of subsidized and paying patients, cost recovery of $100 \%$ of the running cost can be attained.

\section{PROBLEMS}

At present Mechi Eye Care Center is facing problem because of the lack of adequate space and sufficient human resources, mainly Ophthalmologist. Existing premises is overcrowded with the increased numbers of patient flow. Absence of waiting lobby in the out patient department and for the patients undergoing operations makes the situation worse. To cope with the increasing patient load, there is a need for at least two full time ophthalmologists with part time support from one more ophthalmologist during the peak season.

\section{DISCUSSIONS}

The great challenge that Mechi Eye Care Center is facing is to provide quality eye care that is appropriate, affordable and accessible to everyone, especially to the poor of the community. The center is gradually moving towards high volume, low cost approach to eye care delivery so that it can be affordable to everyone and at the same time sustainable in the long run. Hospital charges for operations are provided in a package form to the patients. Patients do not have to buy anything other than the postoperative medicines. Hospital charges are different for the paying patients and the subsidized patients. Patients from the rich group have to pay more so that the patients from the low paying group can be subsidized. Attracting high paying groups require tailoring of services to suit their requirements.

To solve the problem of space, Eye Care Himalaya is planning to build a new well-equipped hospital in a 140,000 Sq. feet land donated by a family trust. This hospital will include all subspecialties in ophthalmology, six modern operation theatres, and two hundred in patient beds. It will also include other support services required for the hospital like microbiology, pathology, radiology departments; eye bank and a low vision clinic. The reason for establishing this large facility is to provide comprehensive eye care to Nepalese population and patients from neighboring India. 
To solve the problem of human resources, Eye Care Himalaya is supporting in the various training activities: training of resident ophthalmologist, fellowship training, ophthalmic assistant training program, and primary eye care worker training. We hope that after completion of new hospital building and with proper and sufficient number of trained human resources at least one thousand patients can be examined and two hundred patients can be operated everyday. Thus, the Hospital will be a gift to the blind people of this region to prevent and cure their blindness and at the same time, it could play a significant role to avoid the avoidable blindness in this part of the world and contribute to the Mission Vision 2020: The Right to Sight.

\section{REFERENCE}

1. Burton M, Fergusson E, Hart A: The prevalence of cataract in two villages of northern Pakistan with different levels of ultraviolet radiation. Eye 1997; 11:95-101.

2. Harding J J, van Heyningen R: Beer, cigarettes and military work as risk factors for cataract. Dev. Ophthalmol , 1989; 17: 13-6.

3. Hu C, Zhao JI, Zhang QN: [ Establishment of a primary eye care network and creation of a cataract free zone in Shunyi County of Beijing]. Chung Hua Yen Ko Tsa Chij , 1994; 30: 134-7.

4. Moll $A C$, van der Linden $A j$, Hogeweg $M$ : Prevalence of blindness and low vision of people over 30 years in the Wenchi district, Ghana, in relation to eye care programmes, $\mathrm{Br}$. J Ophthalmol, 1994; 78:275-9.

5. Ram J: Cataract Blindness in India. Lancet, 1994;343:1228.

6. Schwab L: Cataract blindness in developing nations. Int Ophthalmol Clin 1990; 30:16-8.

7. Taylor A, Nowell T: Oxidative stress and antioxidant function in relationto risk for cataract. Adv Pharmacol , 1997; 38:515-36.

8. West SK, Duncan DD, Munoz B: Sunlight exposure and risk of lens opacities in a population based study: the Salisbury Eye Evaluation project [ see comments]. JAMA, 1998; 280: 714-8.

9. Thylefors B: The World Health Organizations programme for the prevention of blindness. Int Ophthalmol , 1990; 14:211-9.

10. Thylefors B, Negrel AD, Pararajasegaram, Dadzie KY: Available data on blindness. World Health Organization, update 1994, pp 1-34.

11. World Health Organization ( WHO): Available Data on Blindness (Update 1987), Geneva, Switzerland, WHO programme for the Prevention of Blindness, 1987, WHO/PBL/87.14

12. World Health Organization Press Office, Fact sheets February 1997; Parts I-VII; 142-148.

13. Brilliant G E, Pokharel R.P., Grasset N.C., Brilliant L B, 1988; The Epidemiology of Blindness in Nepal, The Seva Foundation.

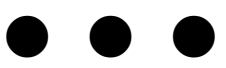

